\title{
Dietary habits of newcomer children in Canada
}

\author{
Ginny Lane ${ }^{1}$, Christine Nisbet ${ }^{2}$ and Hassan Vatanparast ${ }^{1,2, *}$
}

${ }^{1}$ School of Public Health, University of Saskatchewan, 104 Clinic Place, Saskatoon, Saskatchewan, Canada, S7N 2Z4: ${ }^{2}$ College of Pharmacy and Nutrition, University of Saskatchewan, Saskatoon, Saskatchewan, Canada

Submitted 3 October 2018: Final revision received 11 April 2019: Accepted 30 April 2019: First published online 7 August 2019

\begin{abstract}
Objective: To explore the dietary habits, nutrient adequacies and dietary change experiences of immigrant and refugee children.

Design: Mixed-methods cross-sectional design. Children completed three $24 \mathrm{~h}$ dietary recalls to determine nutrient inadequacies. Parents and service providers were interviewed to capture dietary practices.

Setting: Healthy Immigrant Children study, Saskatchewan, Canada.

Participants: Three hundred immigrant and refugee children aged 3-13 years and twenty-two parents who lived in Regina or Saskatoon for less than 5 years; twentyfour newcomer services providers.

Results: Immigrant children had higher mean intakes of meat and alternatives, milk and alternatives, and whole grains; and consumed more vitamin $\mathrm{B}_{12}$, folate, $\mathrm{Ca}$, vitamin D, Fe and Zn compared with refugee children. Refugee children were at higher risk of having inadequate intakes of folate $(37 \%)$ and Fe (18\%). Both immigrant and refugee children were at high risk of inadequate vitamin D (87 and $93 \%$, respectively) and Ca intakes (79 and $80 \%$ ), and a substantial portion were at risk for inadequate $\mathrm{Zn}$ intake (21 and $31 \%$ ). Participants mentioned challenges with maintaining a healthy traditional diet in the midst of a busy schedule, while responding to their children's demands for foods high in fat and sugar. Conclusions: Newcomer children are at risk for inadequate intakes of vitamin D, $\mathrm{Ca}$ and $\mathrm{Zn}$, while refugee children are at additional risk for inadequate folate and $\mathrm{Fe}$ intakes. Newcomers to Canada may experience subtle or drastic changes in their food environment leading to dietary acculturation that includes increased consumption of foods high in sugar, salt and fat.
\end{abstract}

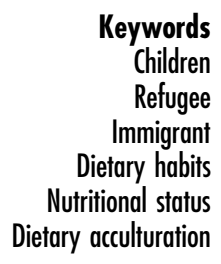

Upon arrival in Canada or other high-income countries, newcomer children may experience subtle or drastic changes in their food environment depending on their pre-migration living circumstances, which may lead to dietary acculturation. Due to the limited availability of published studies on newcomer children, the wider literature on diet among newcomers is included here because children may be offered the same foods consumed by other household members; however, it is not assumed that newcomer children experience exactly the same dietary changes as adults. Many studies have demonstrated that immigrants' increasing exposure to a dominant host culture, as measured by time in the new country, use of the host culture's language and family generation in the new country, is linked to dietary acculturation ${ }^{(1-3)}$. Shifts in the food environment have been linked with shifts in individual dietary intake, but the direction of change is not always consistent ${ }^{(1,4)}$. Among Puerto Rican immigrant women, time spent in the USA has been associated with increased consumption of sweetened drinks, but those with poorer language ability were not as susceptible to this change ${ }^{(1)}$. Similarly, Liberian and Somalian immigrants (adults and children) have been found to consume more sugar and sweets, in addition to vegetables, oils and milk, with increased time spent in the USA; while children among these groups were found to consume more fruit ${ }^{(5)}$. Among Hispanic youths in the USA, exclusive use of the Spanish language in the home has been associated with lower intakes of fat, protein and $\mathrm{Na}$, and higher intake of folate ${ }^{(2)}$. In Australia, sub-Saharan immigrants commonly reported an increased consumption of breakfast cereal, pizza and fast foods after immigration ${ }^{(6)}$. Batis et al. ${ }^{(4)}$ noted that food acculturation among Mexican Americans included both beneficial and deleterious diet modifications. They found that increased exposure to the American culture was linked with increased consumption of low-fat milk, high-fibre 
bread, and low-fat meat and fish, but also noted the increased intake of French fries, pizza, salty snacks, desserts, sugar and saturated fat. Franzen and Smith ${ }^{(3)}$ observed that Hmong refugees in the USA increased their meat consumption and the following generation born in the USA reported that their diets included a larger proportion of American foods and less traditional foods. These studies demonstrate that both adult and child newcomers to high-income countries experience some dietary changes, but it is neither linear, nor exclusively beneficial or deleterious to their health.

It is important to consider the overall food environment both pre- and post-migration to understand how newcomer dietary intake may be affected by the new environment. Pre-migration, refugees may have spent time in refugee camps and experienced food shortages, which may result in abnormal dietary behaviour after the period of deprivation has ended ${ }^{(7,8)}$. Some research suggests that the episodic abundance of food among low-income newcomers, such as the monthly feast and famine cycle of social assistance or food stamps, may be linked to disordered eating and bingeing ${ }^{(9)}$. Food deprivation may also lead to persistent food-related issues such as excessive food storage, food cravings and difficulty throwing away food $^{(10)}$. Franzen and Smith ${ }^{(3)}$ have reported that some Hmong refugees in the USA own two to four freezers to store large quantities of meat so they would always have some available. The transition from a refugee camp, with limited food supplies and no refrigeration, to a high-income country where it is possible to store large amounts of frozen food appears to have shaped food-buying behaviour to favour the purchase and storage of meat, a high-status food.

Immigrants from transitional countries* may have been exposed to pre-migration environments that include processed foods and thus already experienced substantial changes to their dietary patterns, including increased consumption of sugar-sweetened beverages, animal-based foods and processed foods, and decreased consumption of fruits, vegetables and legumes, prior to migrating to Canada ${ }^{(11,12)}$. These dietary changes may have occurred over generations or within the lifetime of some individuals, depending on the pace of development, which tends to be accelerated among higher income groups, often in urban areas $^{(12)}$. These dietary changes have been associated with substantially increased individual energy intakes in Asia and the Middle East $^{(12,13)}$. According to these trends, immigrants from transitional countries, especially those with higher incomes in their country of origin, may be arriving with already established poor dietary habits that predispose them to the development of non-communicable diseases in Canada.

*A low- to middle-income country that is in a transition process based on more liberal, market-friendly structures and associated features of liberal democracy, often accompanied by increased access to and consumption of processed foods with high sugar and fat content.
The availability of traditional foods, economic constraints, time constraints that lead to the use of convenience foods, children's demands and the ability to cook host-country foods can all influence newcomer dietary intake after migration to a new host environment ${ }^{(5)}$. While some newcomers in rural areas may have difficulty locating familiar traditional foods ${ }^{(14)}$, this does not appear to be a major issue for urban newcomers as only $12 \%$ of Liberian and Somalian refugees reported difficulty with locating their preferred foods in a recent American study ${ }^{(5)}$. However, the experience of respondents indicates that they learn where to buy traditional and American foods from their case workers and ethnic peers who arrived earlier, so their social network can influence their food-buying behaviour ${ }^{(2)}$. In addition to the availability of traditional foods in stores, newcomer children's access to traditional foods can be affected by the lack of a mother or other relative responsible for preparing traditional foods. Bowen and Devine ${ }^{(15)}$ found that Puerto Rican girls who migrated to the USA without their mother or grandmother experienced significant dietary change due to lack of access to traditional foods. Time constraints due to newcomer work schedules or lack of transportation may also affect food-buying and preparation behaviour. For example, Hmong refugees in the USA stated that they were not able to access Asian/Hmong food stores frequently due to limited business hours; and they no longer make certain traditional foods because they can purchase those prepared foods at ethnic food shops ${ }^{(3)}$. While lack of availability and time constraints shape food-buying behaviour, economic constraints appear to exert greater influence on food purchasing decisions. For example, African refugees identified the high cost of African foods as an issue leading them to eat African foods only for the first few weeks following receipt of their monthly allocation of food stamps and then turning to a more monotonous diet of soups ${ }^{(5)}$.

Food decisions are also impacted by family dynamics and cooking skill limitations. Newcomer children's food preferences may be influenced by exposure to new hostcountry foods at day-care centres or school food programmes $^{(5)}$ and media advertising ${ }^{(16)}$. Indeed, in one study, $75 \%$ of Liberian and Somalian refugees felt it was important for their children to eat traditional foods, but often complied with their children's demands to purchase American foods because they worried that their children were not eating enough ${ }^{(5)}$. An additional nuance to this finding is that children of parents with poorer English skills consumed more sodas and salty snacks and less fruit, indicating that children with better English skills than their parents may have some influence on dietary decisions. Hmong refugees have also reported that they buy American foods for their children and traditional foods for themselves ${ }^{(3)}$. Dietary decisions may be impacted by knowledge translation of cooking skills among family 
members. Patil et al. ${ }^{(5)}$ found that over $40 \%$ of Liberian refugees agreed that their food habits were shaped by lack of knowledge concerning how to cook alternative foods. Respondents described how they liked some American foods and would like to prepare them at home, but they do not know how to cook them, nor do they have anyone to show them how to cook and/or they cannot read English cookbooks.

There is some evidence that immigrant and refugee children experience different risks with regard to the development of non-communicable disease, which may have roots in dietary practices. A Canadian study observed that significantly more refugee children had stunted growth (23\%) and high blood cholesterol (60\%) compared with immigrants ( 5 and $42 \%$, respectively) ${ }^{(17)}$. In addition, older children, those with better-educated parents and those who consumed a poorer-quality diet were at a higher risk of being overweight or obese, indicating an emerging trend that older children from privileged backgrounds (more commonly immigrants) may be more at risk of overweight and obesity. Given that children establish dietary patterns during their pre-school years ${ }^{(18)}$, the early signs of noncommunicable disease may manifest in childhood ${ }^{(19)}$ and young children often experience successful lifestyle changes as a result of interventions ${ }^{(20)}$, it is important to understand nutrition issues among newcomer children to inform successful dietary interventions.

In 2006, foreign-born Canadians made up about 19\% of the population, and immigration accounts for about $60 \%$ of annual population growth ${ }^{(21)}$. Given the growing immigrant population and under-documentation of immigration-related dietary changes, a Canadian scoping review of the current literature related to immigrant nutritional health to identify potential research priorities was completed in $2014^{(22)}$. That review identified only one study that included children aged 4-13 years. The review identified mechanisms of food choice in immigrant families as a research priority. In addition, the review found that knowledge gaps related to mechanisms of immigrant nutrition and health transitions included immigrant youths' dietary patterns and perceptions, as well as epidemiology of selected micronutrient deficiencies among immigrants.

The available research illustrates the complex, multidimensional nature of newcomer dietary change mediated by the child's, parent's and family's environment. However, much of the available research does not directly compare the dietary changes or nutritional intake of immigrant and refugee children, nor provide possible explanations of observed deficiencies. The current article presents quantitative data that characterize the diets of immigrant and refugee children, as well as qualitative data that describe dietary changes experienced during their time in Canada, which directly responds to the research priorities and knowledge gaps identified in the Canadian scoping review.

\section{Methods}

The Healthy Immigrant Children (HIC) study employed a mixed-method design using a combination of quantitative and qualitative methods in alignment with the critical realist methodological approach ${ }^{(23)}$ to yield complementary data and to allow for methodological triangulation to support a more complete description of the health status of newcomer children and the underlying mechanisms that may influence health outcomes. This 'Methods' section highlights the most relevant methods used for the current $\operatorname{article}^{(17)}$.

The study involved the collection of qualitative data through in-depth interviews with the parents of newcomer children and service providers regarding family diet and dietary changes experienced in Canada. The collection of quantitative data was accomplished through the administration of questionnaires concerning socio-economic status and diet. Information gathered through the questionnaires primarily informed the development of a comprehensive description of newcomer children's usual diet, while the in-depth interviews facilitated rich description of dietary changes and some explanation of the mechanisms behind the dietary changes.

\section{Participant recruitment}

The HIC study involved a cross-sectional analysis of 300 immigrant and refugee children aged 3-13 years who had been living in Regina or Saskatoon, Saskatchewan, Canada for less than 5 years, as this is a time period hypothesized to be sufficient to allow for some dietary adaptation and participant recall of their experiences with dietary changes; however, further dietary changes may occur after this time period so the results may not be generalizable to longer-term foreign-born individuals. Length of time in a host country is the most common dimension of acculturation referred to in regard to dietary changes ${ }^{(22)}$; however, there is no agreement on a specific number of years to encompass the acculturation period. Furthermore, Statistics Canada ${ }^{(24)}$ considers a recent immigrant to be an individual who became a landed immigrant or permanent resident within the 5 years prior to a given census year. The age range of 3-13 years was selected as this includes children who would be largely transitioned from breast-feeding to a normal family diet and excludes older children who may be eating more foods outside their home.

Study participants were purposefully selected to proportionally approximate the sex, ethnicity and countries of origin of the current Saskatchewan newcomer population. During the study period $68.7 \%$ of newcomers to Saskatchewan were from Asia and the Pacific, 9.6\% from Africa and the Middle East, $12.0 \%$ from Europe and the UK, $4.8 \%$ from the USA and $4.9 \%$ were from South and Central America ${ }^{(25)}$. Only healthy children, not currently 
being treated for malnutrition or other serious medical problems, were recruited.

Several newcomer settlement organizations, such as Open Door, assisted with participant recruitment by inviting parents to nominate their children to participate. Parents provided written consent to participate in the study and written confirmation that their children assented to participation. Interviews were conducted in English and interpreters were available as needed to assist the parents and children.

\section{Quantitative data collection and analysis}

With the assistance of their parents, each child was asked to complete three $24 \mathrm{~h}$ dietary recalls, which were completed at least $10 \mathrm{~d}$ apart to allow for assessment of the participant's usual intake as per Gibson ${ }^{(26)}$. Food pictures and diagrams were used to facilitate accurate description and portion size of foods consumed. Parents provided ingredients for mixed dishes. The three $24 \mathrm{~h}$ dietary intakes were averaged to obtain the participant's usual intake. The first $24 \mathrm{~h}$ recall was administered in person on the participant's first study visit, while the two subsequent $24 \mathrm{~h}$ recalls were also usually administered in person due to language barriers and difficulties with describing portion sizes. This methodology is similar to the pilot study with participants of the same age range, as well as other studies by Vatanparast ${ }^{(27)}$

The participants' dietary information was entered into a diet analysis program Food Processor Nutrition and Fitness Software version SQL 10 (Esha Research, Salem, OR, USA) to determine their intakes of food group portions and specific nutrients. This program includes more than 5000 Canadian food items; however, if a specific food was not included in the Canadian food list, the American food item most similar in nutrient content was substituted. The results were analysed to determine whether the children consumed the recommended servings for Vegetables and Fruit, Grain Products, Milk and Alternatives, and Meat and Alternatives described in Eating Well with Canada's Food Guide ${ }^{(28)}$. These results were compared between the groups of refugee and immigrant children. Prevalence of micronutrient inadequacy was calculated based on the Dietary Reference Intakes for age and sex categories.

The Canadian version of the Healthy Eating Index (HEI) was used to assess overall dietary adequacy ${ }^{(29)}$. The HEI was originally created by the US Department of Agriculture. The Canadian version of the HEI (HEI-C) has been validated and is based on the Eating Well with Canada's Food Guide recommendations ${ }^{(28)}$. The HEI-C includes eleven components categorized as either adequate or moderate. The adequacy components include vegetables and fruit, whole fruit, dark green and orange vegetables, grain products, whole grains, milk and alternatives, meat and alternatives, and unsaturated fats.
The moderation components include saturated fats, sodium and other food. The scoring system attributes a certain number of points for each component and points are distributed proportionately based on meeting the Eating Well with Canada's Food Guide recommendations ${ }^{(28)}$. The points are then totalled to provide a score out of the ideal score of 100 . A score of $<50$ is classified as a 'poor' diet, while a score of $50-80$ is classified as 'needs improvement' and a score of $>80$ is classified as 'good'.

Descriptive data are presented as mean and SD to compare refugee children with immigrant children. Data were tested for normal distribution using the Shapiro-Wilk test; when found to be not normally distributed, data were either transformed or subjected to equivalent non-parametric tests (Mann-Whitney $U$ test). A two-sided independent Student's $t$ test was used to evaluate differences between refugees and immigrants.

\section{Qualitative data collection and analysis}

The second phase of the study involved inviting a purposefully selected sample of the participants' parents to participate in in-depth interviews to better understand newcomer family dietary practices and dietary changes experienced in Canada. A diverse selection of refugee and immigrant parents, representing nineteen families of various ethnic and socio-economic backgrounds, participated in in-depth individual or household group interviews. The in-depth interviews focused on rich description of children's diets and dietary changes experienced in Canada. Interviews used open-ended questions to facilitate the collection of rich, descriptive narratives ${ }^{(30)}$. Interviews were conducted until saturation was achieved, as indicated by the lack of any new significant data in the last few interviews conducted.

The parent interview guides started with questions regarding their children's general health and major factors affecting their health. Parents were then asked to describe their children's diet, with probes for consumption of fruits, vegetables and milk products, and barriers to eating a healthy diet. Finally, parents were asked if they had any ideas concerning how to help children eat a healthier diet.

In addition, a purposefully selected key informant sample of newcomer service providers, health-care providers (physicians, paediatricians, dietitians and public health nurses) and policy makers was invited to participate in in-depth interviews to understand their perspectives on newcomer health and diet. A diverse sample of twenty-four participants from a variety of organizations that interact with newcomers in a variety of settings and at different levels was selected to illuminate the diversity of perspectives. Participants included twenty-two service providers from settlement agencies, community schools, English-as-aSecond-Language programmes and health-care organizations, as well as two policy and programme consultants from government departments. All of the selected service 
providers had many years of experience in working with refugees and immigrants and are widely recognized for their expertise. The key informant group had a similar composition to the stakeholder group (immigrant cultural representatives, government agencies, nutrition professional organizations, community health centres and immigrant settlement organizations) invited to participate in a consultation to inform the state of knowledge and research priorities concerning immigrant dietary acculturation ${ }^{(22)}$.

Similar to newcomers' in-depth interviews, questions were open-ended, and interviews were conducted to the point of saturation. The service provider interview guide questions were a rephrased version of the parent interview guide questions to reflect that the questions referred to their experiences with newcomer children in general, not their own children.

Thematic content analysis was used to analyse in-depth interview data using an inductive approach with open coding of early data to generate categories embedded in the data in alignment with grounded theory ${ }^{(31)}$, including the review of deviant cases to capture diverse experiences of the sample population. Interviews were recorded and transcribed verbatim following the sessions, and then reviewed against the audio tapes, at minimum a second time, by the same person. Early interviews were conducted concurrently with data analysis occurring in an iterative process so initial results could be used to open additional lines of investigation and further fine tune participant questions and probing.

Salient data extracts corresponding to the research question were identified in order to generate coding categories across the entire data set, which were then reviewed to identify main themes and collate relevant code categories among them. The identification of themes relied on both number of similarly coded data extracts, as well as divergent experiences of some importance with reference to the research question. Themes were further refined by combining categories and organizing sub-themes under them. Quotes provided by higher-income immigrants from high-income countries were compared with quotes from other participants to identify areas of convergence and contrast. This process supported the transformation of individual narratives into a critique of social processes and structures that organize lived experiences. The software package NVivo version 11 was used to facilitate qualitative data analysis.

The qualitative and quantitative data were explored to identify areas of convergence or triangulation and to more fully explain the results and enhance validity ${ }^{(32)}$. Participants at the All Nations Hope Network's 'The Story of the Visioning Gathering', a research priority and visioning event, emphasized the importance of using qualitative data to contextualize and make sense of quantitative data, otherwise researchers run the risk of misrepresentation ${ }^{(33)}$. The in-depth interview data provided rich insight into lived individual experiences, as well as overcoming the possibility that quantitative data could lead to the development of unwarranted categories and priorities that lead research down a reductionist path ${ }^{(34)}$.

Attention to validity and reliability assured that rigour was achieved ${ }^{(35)}$. In regard to validity, thick description was achieved through prolonged engagement as participants had interacted with the research team on a number of occasions, probing to expand on answers, and attaining data saturation. In addition, data were drawn from both newcomer parents and service providers, which theoretically increased the sample size as service providers were drawing on their experience with a large number of newcomers. Validity was increased by including participants from the two groups, which allowed for triangulation of data from two different sources. Researcher bias was minimized by using an inductive approach and asking about both positive and negative experiences.

Reliability was achieved through using interpretive coding by one researcher. Although semi-structured interview questions were used to guide the interviews, the interview transcripts were more like unstructured interviews as participants covered a variety of topics under any one question and the topics morphed to more specifically inquire about new lines of investigation as interviews proceeded. In alignment with Morse's recommendations ${ }^{(35)}$, coding decisions were made in the context of the knowledge gained from all previous interviews. Data reliability in the Saskatchewan context was supported through using purposeful sampling to draw a sample that represents the ethnic origins of recent newcomers to Saskatchewan. Overlapping interview data from different participants demonstrated the attainment of internal reliability.

\section{Results}

\section{Quantitative results}

\section{Participants' demographics}

Many study participants originated from Asia (49.3\%), the Middle East (28.2\%) and Africa (11.7\%). The largest proportion of refugees was from Asia (68.7\%), while a large majority of immigrants in the study were from the Middle East (49.2\%; Table 1).

\section{Participants' dietary intakes}

Mean intakes of meat and alternatives, milk and alternatives, whole grains, and dark green and orange vegetables varied significantly by immigrant status, with immigrants having the higher mean intake in all cases, except the dark green and orange vegetables category (Table 2). Immigrants were also significantly more likely to consume sufficient servings from the meat and alternatives and whole grains categories. There was not a statistically significant difference between immigrant and refugee children in terms of their HEI-C scores and the proportion that consumed a 'good' diet. 
Table 1 Participant demographics: immigrant and refugee children aged 3-13 years who lived in Regina or Saskatoon (Saskatchewan, Canada) for less than 5 years; Healthy Immigrant Children study, April 2010-June 2015

\begin{tabular}{|c|c|c|c|c|c|c|}
\hline \multirow[b]{2}{*}{ Characteristic } & \multicolumn{2}{|c|}{$\begin{array}{c}\text { Immigrants } \\
(n 134 ; 44.7 \%)\end{array}$} & \multicolumn{2}{|c|}{$\begin{array}{c}\text { Refugees } \\
(n 166 ; 55.3 \%) \\
\end{array}$} & \multicolumn{2}{|c|}{$\begin{array}{l}\text { All participants } \\
\text { (n300; } 100.0 \%)\end{array}$} \\
\hline & Mean or $n$ & SD or $\%$ & Mean or $n$ & SD or $\%$ & Mean or $n$ & SD or $\%$ \\
\hline Age (years), mean and SD & $8 \cdot 3^{*}$ & $2 \cdot 9$ & $7 \cdot 8$ & $2 \cdot 7$ & $8 \cdot 0$ & $2 \cdot 8$ \\
\hline \multicolumn{7}{|l|}{ Sex, $n$ and $\%$} \\
\hline Male & 75 & $56 \cdot 8$ & 102 & 61.4 & 177 & $59 \cdot 4$ \\
\hline Female & 57 & $43 \cdot 2$ & 64 & $38 \cdot 6$ & 121 & $40 \cdot 6$ \\
\hline \multicolumn{7}{|l|}{ Region of origin, $n$ and \% } \\
\hline Middle East (excl. Iran, Iraq, Pakistan) & 65 & $49 \cdot 2^{*}$ & 19 & 11.4 & 84 & $28 \cdot 2$ \\
\hline Asia (excl. Burma, India, Philippines) & 33 & $25 \cdot 0^{*}$ & 114 & $68 \cdot 7$ & 147 & $49 \cdot 3$ \\
\hline Africa & 13 & $9 \cdot 8^{*}$ & 22 & $13 \cdot 3$ & 35 & $11 \cdot 7$ \\
\hline Latin America & 2 & $1.5^{\star}$ & 11 & $6 \cdot 6$ & 13 & 4.4 \\
\hline Eastern Europe & 11 & $8 \cdot 3^{*}$ & 0 & 0.0 & 11 & 3.7 \\
\hline Western Europe/USA & 8 & $6 \cdot 1^{*}$ & 0 & 0.0 & 8 & $2 \cdot 7$ \\
\hline Length of stay in Canada (years), mean and SD & $2 \cdot 0^{*}$ & 1.6 & $2 \cdot 6$ & 1.5 & $2 \cdot 3$ & $1 \cdot 6$ \\
\hline
\end{tabular}

${ }^{*}$ Significant difference in mean value or percentage between immigrants and refugees $\left(\chi^{2}\right.$ test): $P<0.05$.

Table 2 Food group intakes and Canadian Healthy Eating Index (HEI-C) scores of child participants: immigrant and refugee children aged 3-13 years who lived in Regina or Saskatoon (Saskatchewan, Canada) for less than 5 years; Healthy Immigrant Children study, April 2010June 2015

\begin{tabular}{|c|c|c|c|c|c|c|}
\hline \multirow[b]{2}{*}{ Characteristic } & \multicolumn{2}{|c|}{$\begin{array}{c}\text { Immigrants } \\
(n 132 ; 46.3 \%)\end{array}$} & \multicolumn{2}{|c|}{$\begin{array}{c}\text { Refugees } \\
(n 153 ; 53.7 \%)\end{array}$} & \multicolumn{2}{|c|}{$\begin{array}{l}\text { All participants } \\
\text { (n287; 100.0\%) }\end{array}$} \\
\hline & Mean or $n$ & SD or $\%$ & Mean or $n$ & SD or $\%$ & Mean or $n$ & SD or $\%$ \\
\hline \multicolumn{7}{|l|}{ Meat and alternatives } \\
\hline Mean intake (servings/d), mean and SD & $1.8^{*}$ & 1.0 & 1.5 & 0.9 & 1.6 & 1.0 \\
\hline Meeting Canada's Food Guide recommendations ${ }^{(28)}, n$ and \% & 107 & $82 \cdot 3^{*}$ & 103 & $68 \cdot 7$ & 210 & $75 \cdot 0$ \\
\hline \multicolumn{7}{|l|}{ Milk and alternatives } \\
\hline Mean intake (servings/d), mean and SD & $1 \cdot 6^{*}$ & $1 \cdot 1$ & $1 \cdot 3$ & $1 \cdot 0$ & 1.5 & $1 \cdot 1$ \\
\hline Meeting Canada's Food Guide recommendations ${ }^{(28)}, n$ and \% & 31 & $23 \cdot 8$ & 25 & $16 \cdot 3$ & 56 & $19 \cdot 8$ \\
\hline \multicolumn{7}{|l|}{ Grain products } \\
\hline Mean intake (servings/d), mean and SD & 5.4 & $2 \cdot 5$ & 4.9 & $2 \cdot 0$ & $5 \cdot 2$ & $2 \cdot 2$ \\
\hline Meeting Canada's Food Guide recommendations ${ }^{(28)}, n$ and $\%$ & 71 & $55 \cdot 0$ & 74 & $49 \cdot 0$ & 145 & $51 \cdot 8$ \\
\hline \multicolumn{7}{|l|}{ Whole grains } \\
\hline Mean intake (servings/d), mean and SD & $1.2^{*}$ & 1.6 & 0.7 & $1 \cdot 1$ & 0.9 & 1.4 \\
\hline Meeting Canada's Food Guide recommendations ${ }^{(28)}, n$ and \% & 25 & $18 \cdot 9^{*}$ & 15 & $9 \cdot 8$ & 40 & $14 \cdot 0$ \\
\hline \multicolumn{7}{|l|}{ Vegetables and fruit } \\
\hline Mean intake (servings/d), mean and SD & $3 \cdot 8$ & $2 \cdot 0$ & $4 \cdot 1$ & $2 \cdot 0$ & $4 \cdot 0$ & $2 \cdot 0$ \\
\hline Meeting Canada's Food Guide recommendations ${ }^{(28)}, n$ and \% & 23 & $17 \cdot 7$ & 40 & $26 \cdot 1$ & 63 & $22 \cdot 3$ \\
\hline \multicolumn{7}{|l|}{ Dark green and orange vegetables } \\
\hline Mean intake (servings/d), mean and SD & $0.3^{*}$ & 0.4 & 0.4 & 0.5 & 0.4 & 0.5 \\
\hline Meeting Canada's Food Guide recommendations ${ }^{(28)}, n$ and \% & 1 & 0.8 & 5 & $3 \cdot 3$ & 6 & $2 \cdot 1$ \\
\hline \multicolumn{7}{|l|}{ HEI-C } \\
\hline Score, mean and SD & 73.7 & $7 \cdot 5$ & $72 \cdot 0$ & $8 \cdot 3$ & $72 \cdot 8$ & $8 \cdot 0$ \\
\hline 'Good' diet, $n$ and \% & 29 & $22 \cdot 3$ & 22 & 14.4 & 51 & $18 \cdot 0$ \\
\hline Diet 'needs improvement', $n$ and \% & 101 & $77 \cdot 7$ & 131 & $85 \cdot 6$ & 232 & 82.0 \\
\hline 'Poor' diet, $n$ and \% & 0 & 0.0 & 0 & 0.0 & 0 & 0.0 \\
\hline
\end{tabular}

*Significant difference in mean value or percentage between immigrants and refugees $\left(x^{2}\right.$ test): $P<0.05$.

In terms of mean daily intakes of macronutrients, immigrants consumed significantly more in all categories, including total energy, energy from fat and saturated fat, and protein (Table 3 ). Only $3 \%$ of participants had an inadequate intake of protein and $2 \%$ had an inadequate intake of carbohydrate. Overall, participants consumed a low daily amount of fibre (mean $=12 \mathrm{~g}$ ), with only $3 \%$ of participants having consumed sufficient fibre to meet the daily requirement.
In terms of mean daily intakes of micronutrients, immigrants consumed significantly more vitamin $\mathrm{B}_{12}$, folate, Ca, vitamin $\mathrm{D}, \mathrm{Fe}$ and $\mathrm{Zn}$. As may be expected from these results, higher levels of inadequate micronutrient intakes were observed among refugee children, which included a significantly higher risk of having an inadequate intake of folate and $\mathrm{Fe}$. Both immigrant and refugee children were at high risk of inadequate vitamin D (87 and $93 \%$, respectively) and Ca intakes (79 and 
Table 3 Nutrient intakes of child participants: immigrant and refugee children aged 3-13 years who lived in Regina or Saskatoon (Saskatchewan, Canada) for less than 5 years; Healthy Immigrant Children study, April 2010-June 2015

\begin{tabular}{|c|c|c|c|c|c|c|}
\hline \multirow[b]{2}{*}{ Daily nutrient intake } & \multicolumn{2}{|c|}{$\begin{array}{c}\text { Immigrants } \\
(n 133 ; 46.5 \%)\end{array}$} & \multicolumn{2}{|c|}{$\begin{array}{c}\text { Refugees } \\
\text { (n 153; 53.5\%) }\end{array}$} & \multicolumn{2}{|c|}{$\begin{array}{l}\text { All participants } \\
(n 286 ; 100.0 \%)\end{array}$} \\
\hline & Mean or $n$ & SD or $\%$ & Mean or $n$ & SD or $\%$ & Mean or $n$ & SD or $\%$ \\
\hline Total energy (kJ), mean and SD & $7205^{\star}$ & 2297 & 6054 & 1975 & 6590 & 2205 \\
\hline Total energy (kcal), mean and SD & $1722^{*}$ & 549 & 1447 & 472 & 1575 & 527 \\
\hline Energy intake from fat $(\mathrm{kJ})$, mean and SD & $2205^{*}$ & 833 & 1845 & 833 & 2013 & 849 \\
\hline Energy intake from fat (kcal), mean and SD & $527^{\star}$ & 199 & 441 & 199 & 481 & 203 \\
\hline Energy intake from saturated fat $(\mathrm{kJ})$, mean and SD & $745^{\star}$ & 310 & 628 & 289 & 682 & 305 \\
\hline Energy intake from saturated fat (kcal), mean and SD & $178^{*}$ & 74 & 150 & 69 & 163 & 73 \\
\hline Protein intake $(\mathrm{g})$, mean and SD & $63^{*}$ & 21 & 51 & 20 & 57 & 22 \\
\hline Prevalence of intake inadequacy, $n$ and $\%$ & 2 & 1.5 & 7 & $4 \cdot 6$ & 9 & 3.2 \\
\hline Carbohydrate intake $(\mathrm{g})$, mean and SD & $243^{*}$ & 86 & 203 & 63 & 221 & 77 \\
\hline Prevalence of intake inadequacy, $n$ and $\%$ & 2 & 1.5 & 4 & $2 \cdot 6$ & 6 & $2 \cdot 1$ \\
\hline Fibre intake $(\mathrm{g})$, mean and SD & $14^{*}$ & 7 & 11 & 4 & 12 & 6 \\
\hline Prevalence of intake inadequacy, $n$ and $\%$ & 122 & $93^{*}$ & 153 & 99 & 275 & 97 \\
\hline Sugar intake $(\mathrm{g})$, mean and SD & $89^{*}$ & 36 & 68 & 34 & 78 & 36 \\
\hline Fat intake $(\mathrm{g})$, mean and SD & $59^{*}$ & 22 & 49 & 22 & 54 & 23 \\
\hline Saturated fat intake $(\mathrm{g})$, mean and SD & $20^{\star}$ & 8 & 17 & 8 & 18 & 8 \\
\hline Vitamin $B_{12}$ intake $(\mu \mathrm{g})$, mean and SD & $4^{*}$ & 5 & 3 & 2 & 4 & 4 \\
\hline Prevalence of intake inadequacy, $n$ and $\%$ & 9 & 7 & 19 & 12 & 28 & 10 \\
\hline Folate intake (DFE), mean and SD & $323^{*}$ & 196 & 244 & 125 & 281 & 166 \\
\hline Prevalence of intake inadequacy, $n$ and $\%$ & 29 & $22^{*}$ & 57 & 37 & 86 & 30 \\
\hline Ca intake $(\mathrm{mg})$, mean and SD & $723^{*}$ & 353 & 596 & 321 & 655 & 342 \\
\hline Prevalence of intake inadequacy, $n$ and $\%$ & 103 & 79 & 123 & 80 & 226 & 80 \\
\hline Vitamin D intake $(\mu \mathrm{g})$, mean and SD & $5 \cdot 9^{*}$ & $5 \cdot 7$ & 3.9 & 3.0 & 4.9 & 4.5 \\
\hline Vitamin D intake (IU), mean and SD & $236^{*}$ & 226 & 157 & 119 & 194 & 181 \\
\hline Prevalence of intake inadequacy, $n$ and $\%$ & 116 & 87 & 142 & 93 & 258 & 91 \\
\hline Iron intake (mg), mean and SD & $12^{*}$ & 5 & 8 & 7 & 10 & 6 \\
\hline Prevalence of intake inadequacy, $n$ and \% & 0 & $0^{*}$ & 28 & 18 & 28 & 10 \\
\hline Na intake $(\mathrm{mg})$, mean and SD & $2278^{*}$ & 1058 & 1988 & 1251 & 2117 & 1177 \\
\hline Prevalence of intake inadequacy, $n$ and \% & 20 & 15 & 31 & 20 & 51 & 18 \\
\hline Na intake above UL, $n$ and $\%$ & 67 & 51 & 74 & 48 & 141 & 50 \\
\hline Zn intake (mg), mean and SD & $8^{*}$ & 4 & 6 & 3 & 7 & 3 \\
\hline Prevalence of intake inadequacy, $n$ and \% & 28 & 21 & 48 & 31 & 76 & 27 \\
\hline
\end{tabular}

DFE, dietary folate equivalents; UL, upper limit.

${ }^{*}$ Significant difference in mean value or percentage between immigrants and refugees $\left(\chi^{2}\right.$ test): $P<0.05$.

$80 \%$, respectively). This is consistent with the low consumption of milk and alternatives (good sources of vitamin $\mathrm{D}$ and $\mathrm{Ca}$ ) by all participants.

\section{Qualitative results}

All newcomer participants were parents of children between the ages of 3 and 13 years. They were not asked to provide their exact age. Parents from nineteen distinct family units were interviewed, including fifteen mothers and seven fathers. In three cases both the mother and father participated as a couple. Participants included thirteen immigrants and nine refugees. Participants were from the USA ( $n 2)$, Western Europe $(n 2)$, Eastern Europe ( $n 1)$, Latin America ( $n 1)$, Africa ( $n 2)$, Asia ( $n$ 6) and the Middle East ( $n 8$ ). Families from the USA and Western Europe reported high incomes, one Middle Eastern and one Latin American family reported middle incomes, while all others reported low incomes. Service providers were not asked to provide demographic information.

Through the process of thematic analysis, dietary acculturation emerged as a main theme, with vitamin deficiencies as a sub-theme. Many newcomer parents talked about the challenges of trying to maintain a traditional diet for their family in the midst of a busy schedule and their children's demands to eat more fast foods and sugar-sweetened beverages. A Regina refugee described how his children's diet was changing to include more fast foods and sugar-sweetened beverages:

'It's a different diet here ... The kids want to buy pop to drink ... They still eat traditional food, but they usually in Canada like to eat pizza, burgers and sandwiches ... But now they don't like rice too much.'

Another Regina refugee emphasized how the fast-paced lifestyle was transforming her children's diet:

'Comparing to back home it [diet] has changed a lot ... My kids here they prefer to eat junk food, like they want to go to McDonalds and eat something very quickly ... they will make something like waffles and they will eat very quickly without thinking about any kind of vegetables.'

Some parents also mentioned that their families were consuming more meat. A Saskatoon refugee commented: 
'Here in Canada we eat more meat. Here it is cheaper for meat, more affordable ... He [son] drinks coke almost every day, chips once in a while. This is different than back home.'

Parents are trying to balance providing a healthy diet to their children, while also responding to their expressed needs for snack foods and sodas. A Saskatoon immigrant expressed concerns with her daughter:

'I tell them whenever you are going in the morning first have a good breakfast, whatever you want, there are fruits, vegetables, but they just want the routine ... she likes pizza, ... Here they are very much fond of chocolates, fast foods, chips, fries, ice cream, what they want is that very easy thing, just take-out pizza, put it in the microwave and there it is, ready to eat.'

Some parents spoke about the primacy of ensuring that their children's needs are met and that they don't feel deprived. A Saskatoon refugee explained:

'The middle son eats coke, chips and chocolate ... every day, whenever he is hungry ... We are eating it more here and more food in general ... The children ask for those things so if dad does not buy them they get angry, so he buys it.'

In contrast, some immigrants from high-income countries appeared to be more attuned to dietary problems and better equipped to handle these challenges, perhaps due to having nutritional knowledge about the host-country diet and greater financial resources. A Regina immigrant from Germany stated:

'Once in a while, chips are for us a treat, may be for a movie night once a month, I don't buy them regularly. And we do not have pop in the house, only lemonade from the powder once in a while. We drink mainly water and tea and some juice.'

A Regina immigrant from the UK spoke about her concerted efforts to ensure her daughter has an adequate diet:

'They do eat loads of fruit and vegetables; we do push that on them. [Daughter] wouldn't have milk products, but now she started having a cup of milk each night ... We are getting a bit further with her ... She won't eat red meat so she will eat it in a lasagne or meat balls so we offer that once or twice a week ... we gave her supplements to make sure she is getting the right amounts.'

Health-care providers commonly noted that among the newcomer families they see, many eat a high-carbohydrate and meat-based diet, often consume sugar-sweetened beverages and rarely consume milk products. A Saskatoon health-care provider observed:

'Most of the families that I see have a diet based on carbohydrate, whether it is rice or cassava or maize ... a family here not too long along, older children, teenagers, but the diet recall was, I could not believe the lack of vegetables and fruit. It was purely all carbs, like macaroni.'

Another Saskatoon health-care provider shared:

'When they came they were craving meat so they buy nothing but meat. They don't eat fruits or vegetables, and ... those children like pop, they drink a lot of pop because it's cheap and accessible.'

A Regina health-care provider emphasized the challenges with milk consumption:

'Some cultures never saw milk, they were in camps ... they don't have that good source of milk so none of them drink milk except when they were breast-fed ... continue on the same path and they were not giving milk to their children ... a big challenge ... if you are not used to something when you grow up you don't want to add it now.'

Immigrant service providers focused on the cultural aspect to dietary practices that continue in Canada, as well as the possible overconsumption of meat in response to experiencing deprivation in refugee camps. A Saskatoon immigrant service provider noted:

'It's a cultural thing [dietary practices] ... in Bangladesh teenagers don't drink milk, only ... when they are babies, young children up to 5 or 6 years ... After refugee camps and coming here they buy a lot of meat because they didn't get it. Also a lot of bread.'

Health-care providers commonly noticed that newcomer children are often deficient in Fe, vitamin $\mathrm{B}_{12}$ and vitamin D. A Regina health-care provider who sees many refugees explained:

' $85 \%$ of children and women who come to this office are anaemic ... because these people lived in camps ... they were never given meat ... vitamin $D$ is another one, even adults are vitamin D deficient ... I have patients who are deficient in vitamin $B_{12}$, but not in a very high number ... more deficient in the people who don't take a lot of grains [fortified] and ... some of them didn't eat that much egg.'

Similarly, another Regina health-care provider added:

'The most common health issues would be iron deficiency ... meat is too expensive, they don't seem to be having the iron-fortified foods like cereals and breads ... and not a lot of vitamin $\mathrm{C}$ because of the lack of fruits and vegetables.'

A Saskatoon health-care provider perceived:

'Vitamin D deficiency in everyone. I have even stopped testing them for it and I just supplement them ... Vitamin $\mathrm{B}_{12}$ deficiency to some degree in certain categories of migrants ... iron-deficiency anaemia for sure.' 
These vitamin deficiencies were often associated with vegetarian diets and low consumption of meat, fortified grains and milk products. In addition, they noted that newcomer children often do not consume the recommended quantities of fruits, so may be lacking vitamin C.

In regard to vitamin $\mathrm{D}$ deficiency, an immigrant service provider stressed that the risk of deficiency among newcomers is related to the change in environmental conditions experienced by moving to a northern country, not poverty. She stated:

'Coming from Africa ... the skin type we have it doesn't store ... vitamin D, because it's always there in Africa, so when you move here it changes ... For me this vitamin D issue should not be linked to poverty because when you are in your own environment, your physique ... it's adapted to that environment so you really don't need to go drink milk to get your vitamin D, you get it from other sources ... When people come they should be given the education that now you have changed your environment ... you need to be consciously [seeking vitamin D].'

However, some newcomers may not have sufficient resources to purchase vitamin supplements if needed as mentioned by a Saskatoon immigrant service provider:

'Usually when you want extra vitamins you have to buy them ... When you talk about the immigrants or refugee family who do not have enough income even if they need some of those complementary vitamins or minerals, they can't afford that.'

\section{Discussion}

Similar to Canadian-born children, newcomer children had inadequate vitamin D (91\%) and Ca (80\%) intakes. This is consistent with their low consumption of milk and alternatives as only $24 \%$ of immigrants and $16 \%$ of refugees consumed sufficient servings of milk and alternatives according to Canada's Food Guide ${ }^{(28)}$. Canadian children up to 8 years of age generally consume diets that provide adequate amounts of most vitamins and minerals, with the exception of $\mathrm{Ca}$ and vitamin $\mathrm{D}^{(36,37)}$. A large proportion of Canadian children do not have adequate intakes of vitamin $\mathrm{D}$ (84.5 to $93.1 \%$ depending on age and sex) and $\mathrm{Ca}(23.0$ to $66.9 \%$ depending on age and sex $)^{(36,37)}$. Inadequate vitamin D consumption among study participants is also consistent with the high rate of insufficient/deficient serum vitamin D observed among the same group of immigrant (53\%) and refugee children $(72 \%)^{(17)}$.

According to study results, many newcomer children also had inadequate intakes of folate (30\%) and $\mathrm{Zn}$ ( $27 \%)$. Inadequate folate consumption is likely due to not consuming sufficient servings of vegetables and fruit, as $78 \%$ of participants did not meet Canada's Food
Guide recommendations ${ }^{(28)}$ in this area. Similarly, an inadequate intake of $\mathrm{Zn}$ is likely linked to not consuming sufficient servings of meat and alternatives as $25 \%$ of participants did not meet the recommended number of servings. In addition, refugees are at additional risk for inadequate intakes of vitamin $\mathrm{B}_{12}(12 \%)$ and $\mathrm{Fe}(18 \%)$. This is likely associated with the higher proportion of refugees who did not consume the recommended number of meat and alternative servings (31\%) as compared with immigrants (18\%), and may also be linked to the consumption of a vegetarian diet.

Also similar to Canadian children, a large proportion of newcomer children consumed too much $\mathrm{Na}$, above the upper limit ( $50 \%$ ); however, this appears to be less prevalent than among Canadian-born children as 77 to $97 \%$ (depending on age and sex) have intake of Na exceeding the upper limit ${ }^{(36,37)}$. High Na consumption has been linked with hypertension among the same group of newcomer children $^{(17)}$.

Comments from health-care providers indicate that they are aware of newcomer children being deficient in Fe, vitamin $B_{12}$ and vitamin $\mathrm{D}$. Their comments link these deficiencies with vegetarian diets and low consumption of meat, fortified grains and milk products. However, health-care providers do not seem to be as aware of the fairly common possibility of $\mathrm{Ca}, \mathrm{Zn}$ and folate deficiencies.

Many of the nutritional deficiencies noted above align with previous research, which indicates newcomer children to high-income countries may be at risk for selected micronutrient deficiencies related to low income, traditional dietary practices and/or lifestyle habits that limit exposure to sunlight. Specific nutrient deficiencies noted among newcomer children include Fe, Zn, vitamin A, folate and vitamin $\mathrm{D}^{(38-42)}$. Omand et al. ${ }^{(42)}$ suggest that vitamin D deficiency is likely related to intake of cow's milk intake, vitamin D supplementation, season and age, as these variables appear to be explanatory factors that mediate the relationship between immigration status and vitamin D status.

The specific nutritional deficiencies observed among newcomer children indicate the importance of access to healthy food and the need for nutritional screening, as well as nutrition education tailored to newcomers. According to participant comments, nutrition education materials need to explain the link between environmental changes and vitamin deficiencies, as well as how diets can be modified to include more $\mathrm{Fe}$, vitamin $\mathrm{D}$ and $\mathrm{B}_{12}$ while still respecting cultural and religious dietary practices. The Saskatoon immigrant service provider who stressed the important link between environmental change and vitamin D deficiency appeared to be inferring that it is important not to understand a diet from a Western standpoint, especially if we are to fully understand issues around dietary habits and respond appropriately.

The overall low consumption of milk and alternatives and vegetable and fruit servings noted among study 
participants is consistent with health-care provider comments that many newcomer children eat a high-carbohydrate and meat-based diet and do not consume many milk products. Immigrant service providers noted concerns with possible overconsumption of meat in response to experiencing deprivation in refugee camps; however, this was not consistent with the quantitative data. Perhaps there are different perceptions about appropriate quantities of meat to consume as compared with Canada's Food Guide ${ }^{(28)}$ or these comments are related to the major dietary changes as newcomers shift from a grain- and pulse-based diet to include more meat when they arrive in Canada.

In regard to HEI-C scores ${ }^{(29)}$, newcomer children in the current study may be doing a little bit better than Canadianborn children as their average score is $72.8 \%$ and $82 \%$ of them are in the diet 'needs improvement' category, with the remainder in the 'good' diet category. In comparison, all groups of Canadian children between the ages of 4 and 13 years have average scores in the diet 'needs improvement' category (ranges from 59.7 to $65.4 \%$ ) and the large majority of each age group has scores in this category (ranges from 91.3 to $96.5 \%)^{(29)}$.

The large proportion of participants with a healthy eating score in the diet 'needs improvement' category is consistent with many comments from parents and service providers about concerns with newcomer children's diets. However, data extracts demonstrate that not all newcomer families experience the same dietary challenges in Canada. Refugees and immigrants from low- to middle-income countries are trying to maintain healthy traditional diets for their children, but they are challenged by children's demands for fast foods and sugar-sweetened beverages. Perhaps their cultural perspectives that place a priority on meeting the needs of their children, combined with previous experiences of deprivation and/or lack of nutritional knowledge concerning the host-country diet, influence families to comply with their children's expressed needs to bring snack foods into the house. However, families from higher-income areas have likely already experienced these challenges and appear to be better prepared to set limits and not purchase unhealthy foods.

Immigrants' increasing exposure to a dominant host culture is shown to be linked to dietary acculturation to a diet high in sugar and fat ${ }^{(2,5)}$. However, the change is not always consistently related to time in the new host country, as increased English-language proficiency has been linked with increased consumption of sweetened drinks ${ }^{(1)}$ and the exclusive use of Spanish language in the home has been associated with maintenance of healthy traditional diets $^{(2)}$. In addition, beneficial dietary changes have been observed among some immigrant groups, including increased consumption of vegetables, milk, fruit ${ }^{(5)}$, lowfat milk, high-fibre bread and low-fat meat ${ }^{(3)}$ and fish ${ }^{(4)}$. These research findings align well with participant comments relating to dietary acculturation, but it is neither linear, nor exclusively beneficial or deleterious to the health of immigrants.

Newcomers' comments about their children's diets suggest that there is an underlying structure to the Canadian food environment that is setting the stage for the development of obesity and other non-communicable health problems among newcomer children. Not all parents understand that consumption of these foods can lead to health problems, so they exert varying levels of agency with regard to setting limits on their children's consumption of these foods.

The service providers' comments are generally consistent with the comments from newcomers from low- to middle-income countries. Some of the service providers work in targeted programmes that would only see this type of clientele, while others may not think of immigrants from the USA or the UK as newcomers as they tend to integrate quite well into Canadian culture. The in-depth interviews expose a social structure where, perhaps unintentionally, racialized groups appear to be viewed as the newcomers or the 'other' that does not fit into Canadian society. Although often unconscious, these assumptions may give rise to bias in the health and social system structure and lead to compartmentalized planning that fails to fully meet the diverse needs of newcomers.

Summarily, current study results align with much of the available research that suggests that dietary intake changes may be affected by the availability of traditional foods, economic constraints, time constraints that lead to the use of convenience foods, children's demands and the ability to cook host-country foods ${ }^{(5)}$. Newcomer children may develop high-fat and high-sugar food preferences due to exposure to new host-country foods at day-care centres or school food programmes ${ }^{(5)}$, or through media advertising $^{(16)}$. Overall, newcomer dietary change is a complex, multidimensional process impacted by the child's, parent's and family's environment.

The dietary inadequacies noted above indicate that newcomer children may be at risk for suboptimal bone development, poor growth and anaemia. Adequate body supplies of both Ca and vitamin D are keys to ensuring optimal bone mass gain during growth. A positive correlation has been observed between dietary $\mathrm{Ca}$ intake and bone mineral mass during childhood and adolescence ${ }^{(43)}$. Serum vitamin D (25-hdyroxycholecalciferol) levels before age 12 years have been positively associated with higher bone mass gain among adolescents at age 15 years ${ }^{(44)}$.

The prevalence of inadequate $\mathrm{Zn}$ intake (27\%) observed among the newcomer children is a concern because it can result in stunting and poor development ${ }^{(45)}$. Among the same study participants, significantly more refugee children (23\%) had stunted growth compared with immigrant children $(5 \%)^{(17)}$. The primary clinical feature of mild $\mathrm{Zn}$ deficiency among children is impaired growth that improves with $\mathrm{Zn}$ supplementation ${ }^{(46)}$. High dietary phytate consumption can impede $\mathrm{Zn}$ absorption ${ }^{(47)}$, while 
consumption of animal protein can enhance absorption ${ }^{(48)}$. Thus, the consumption of vegetarian diets with high phytate content may increase their risk of stunting.

The inadequate consumption of folate, vitamin $\mathrm{B}_{12}$ and $\mathrm{Fe}$ among newcomer children, especially refugees, is also concerning since deficiency in one or more of these micronutrients can result in anaemia ${ }^{(49)}$. Anaemia has been associated with delayed growth, impaired cognitive development and behavioural changes in children related to attention span, intelligence, sensory perception, emotions and behaviour, which may persist into adulthood without treatment $^{(50,51)}$. Similar to $\mathrm{Zn}$, Fe absorption can be inhibited by high dietary phytate consumption ${ }^{(52)}$ and enhanced through the consumption of Fe from animal sources ${ }^{(49)}$. In addition, exclusive breast-feeding after 6 months of age without the introduction of Fe-rich complementary foods or Fe supplements, the consumption of cow's milk and frequent consumption of tea are risk factors for Fe deficiency among newly arrived refugee children ${ }^{(53)}$.

In addition to $\mathrm{Fe}$, an adequate supply of vitamin $\mathrm{B}_{12}$ and folate is required for normal blood cell formation and neurological function ${ }^{(49)}$. Vitamin $\mathrm{B}_{12}$ is normally obtained from animal-source foods, as well as fortified readyto-eat cereals; while folate is found in ready-to-eat cereals, breads and some fruits and vegetables ${ }^{(49)}$. Newcomer children in the current study did not commonly report eating ready-to-eat cereals, an important source of vitamin $\mathrm{B}_{12}$ and folate in the Canadian diet. Since the newcomer children more commonly consumed rice and unleavened bread and some were vegetarian, a substantial number are at risk for anaemia.

\section{Strengths and limitations}

The sample is made up of participants that reflect the countries of origin of newcomers to Saskatchewan and data were analysed to highlight different concerns among refugees and immigrants. Thus, results provide some baseline information to inform health-care system planning.

Only one school-based service provider participated in the interviews. More efforts could be made to gather data from school-based sources to inform a comprehensive description of newcomer children's diets.

\section{Conclusion}

In general, ethnic minority newcomer children are at high risk of inadequate vitamin $\mathrm{D}$ and $\mathrm{Ca}$ intakes, and a substantial portion is at risk for inadequate $\mathrm{Zn}$ intake. In addition, refugee children are at risk of having inadequate intakes of folate and Fe. Participant comments suggest that newcomer children's diets are shaped by the interaction of parents' beliefs and attitudes and children's demands in the context of the host-country food environment that encourages the consumption of processed foods high in sugar, salt and fat. Efforts to screen newcomer children for dietary inadequacies should be paired with culturally appropriate health promotion programming to support newcomer families.

\section{Acknowledgements}

Financial support: This research received no specific grant from any funding agency in the public, commercial or notfor-profit sectors. Conflict of interest: None. Authorship: All authors were involved in the implementation and analysis of the project. H.V. was primarily responsible for the project's conception. G.L. is the primary author responsible for producing drafts of the article. All authors were involved in revisions of the article and have approved the final version. Ethics of human subject participation: This study was conducted according to the guidelines laid down in the Declaration of Helsinki and all procedures involving research study participants were approved by the University of Saskatchewan Research Ethics Committee. Written informed consent was obtained from all participants.

\section{References}

1. Himmelgreen D, Perez-Escamilla R, Peng Y et al. (2005) Birthplace, length of time in the US and language are associated with diet among inner-city Puerto Rican women. Ecol Food Nutr 44, 105-122.

2. Mazur R, Marquis G \& Jensen H (2003) Diet and food insufficiency among Hispanic youths: acculturation and socioeconomic factors in the third National Health and Nutrition Examination Survey. Am J Clin Nutr 78, 1120-1127.

3. Franzen L \& Smith C (2010) Food system access, shopping behavior, and influences on purchasing groceries in adult Hmong living in Minnesota. Am J Health Promot 24, 396409.

4. Batis, C, Hernandez-Barrera L, Barquera S et al. (2011) Food acculturation drives dietary differences among Mexicans, Mexican Americans, and non-Hispanic whites. J Nutr 141, 1898-1906.

5. Patil C, Hadley C \& Nahayo P (2009) Unpacking dietary acculturation among new Americans: results from formative research with African refugees. J Immigr Minor Health 11, 342-358.

6. Renzaho A \& Burns C (2006) Post-migration food habits of sub-Saharan African migrants in Victoria: a cross-sectional study. Nutr Diet 63, 91-102.

7. Toole M \& Waldman R (1997) The public health aspects of complex emergencies and refugee situations. Annu Rev Public Health 18, 283-312.

8. Polivy J, Zeitlin S, Herman C et al. (1994) Food restriction and binge eating: a study of former prisoners of war. J Abnorm Psychol 103, 409-411.

9. Alaimo K, Olson C \& Frongillo E (2001) Low family income and food insufficiency in relation to overweight in US children: is there a paradox? Arch Pediatr Adolesc Med 155, $1161-1167$.

10. Sindler A, Wellman N \& Stier O (2004) Holocaust survivors report long-term effects on attitudes toward food. $J$ Nutr Educ Behav 36, 189-196.

11. Popkin B (2006) Global nutrition dynamics: the world is shifting rapidly toward a diet linked with noncommunicable diseases. Am J Clin Nutr 84, 289-298. 
12. Wang Z, Zhai F \& Du S (2008) Dynamic shifts in Chinese eating behaviors. Asia Pac J Clin Nutr 17, 123-130.

13. Popkin B, Lu B \& Zhai F (2002) Understanding the nutrition transition: measuring rapid dietary changes in transitional countries. Public Health Nutr 5, 947-953.

14. Kaufman P (1999) Rural poor have less access to supermarkets, large grocery stores. Rural Dev Perspect 13, 19-26.

15. Bowen R \& Devine C (2011) Watching a person who knows how to cook, you'll learn a lot. Linked lives, cultural transmission, and the food choices of Puerto Rican girls. Appetite $\mathbf{5 6}$ 290-298.

16. Story M \& French S (2004) Food advertising and marketing directed at children and adolescents in the US. Int J Behav Nutr Phys Act 1, 3 .

17. Lang G, Farag M, White J et al. (2018) Chronic health disparities among refugee and immigrant children in Canada. Appl Physiol Nutr Metab 43, 1043-1058.

18. Teegarden D, Lyle RM, Proulx WR et al. (1999) Previous milk consumption is associated with greater bone density in young women. Am J Clin Nutr 69, 1014-1017.

19. Joliffe C \& Janssen I (2007) Development of age-specific adolescent metabolic syndrome criteria that are linked to the Adult Treatment Panel III and International Diabetes Federation criteria. J Am Coll Cardiol 49, 891-898.

20. Eliakim A, Nemet D, Balakirski Y et al. (2007) The effects of nutritional-physical activity school-based intervention on fatness and fitness in preschool children. J Pediatr Endocrinol Metab 20, 711-718.

21. Chui T, Tran K \& Maheux H (2006) 2006 Census: Immigration in Canada: A Portrait of the Foreign-born Population, 2006 Census: Findings. Statistics Canada no. 97-557-XIF. http:// www12.statcan.ca/census-recensement/2006/as-sa/97-557/ index-eng.cfm (accessed March 2019).

22. Sanou D, O'Reilly E, Ngnie-Teta I et al. (2014) Acculturation and nutritional health of immigrants in Canada: a scoping review. J Immigr Minor Health 16, 24-34.

23. Danermark B, Ekstrom M, Jakobsen L et al. (2002) Explaining Society: Critical Realism in the Social Sciences. New York: Routledge Books.

24. Statistics Canada (2017) 2016 Census of Population: Immigration and Ethnocultural Diversity. https://www12. statcan.gc.ca/census-recensement/2016/ref/98-501/98-501x2016008-eng.cfm\#a1 (accessed April 2019).

25. Citizenship and Immigration Canada (2012) Canada Facts and Figures: Immigration Overview Permanent and Temporary Residents 2012. http://www.cic.gc.ca/english/ pdf/research-stats/facts2012.pdf (accessed June 2018).

26. Gibson R (2005) Measuring food consumption of individuals. In Principles of Nutritional Assessment, 2nd ed., pp. 41-49 [R Gibson, editor]. New York: Oxford University Press.

27. Vatanparast H, Baxter-Jones A, Faulkner RA et al. (2005) Positive effects of vegetable and fruit consumption and calcium intake on bone mineral accrual in boys during growth from childhood to adolescence: the University of Saskatchewan Pediatric Bone Mineral Accrual Study. Am J Clin Nutr 82, 700-706.

28. Health Canada (2012) Eating Well with Canada's Food Guide. https://www.canada.ca/content/dam/hc-sc/migration/hcsc/fn-an/alt_formats/hpfb-dgpsa/pdf/food-guide-aliment/ print_eatwell_bienmang-eng.pdf (accessed July 2019).

29. Garriguet D (2009) Diet quality in Canada. Health Rep 20 , issue $3,41-52$.

30. Morse J \& Field P (1995) Qualitative Research Methods for Health Professionals, 2nd ed. Thousand Oaks, CA: SAGE Publications, Inc

31. Green J \& Thorogood N (2007) Qualitative Methods for Health Research. Thousand Oaks, CA: Sage Publications, Inc.

32. Sands R \& Roer-Strier D (2006) Using data triangulation of mother and daughter interviews to enhance research about families. Qual Soc Work 5, 237-260.
33. Riehl G (2019) The Story of the Visioning Gathering. Regina: All Nations Hope Network.

34. Young D, Spitzer D \& Pang F (1999) Understanding the Health Care needs of Canadian Immigrants. Report submitted to the Prairie Centre for Excellence on Immigration and Integration. https://sites.ualberta.ca/ pcerii/Virtual\%20Library/ FinalReports/young99.htm (accessed June 2018).

35. Morse J (2015) Critical analysis of strategies for determining rigor in qualitative inquiry. Qual Health Res 25, 1212-1222.

36. Health Canada (2012) Do Canadian children meet their nutrient requirements through food intake alone? http:// www.hc-sc.gc.ca/fn-an/surveill/nutrition/commun/art-nutrchild-enf-eng.php\#b1 (accessed June 2018).

37. Health Canada (2012) Do Canadian adolescents meet their nutrient requirements through food intake alone? http:// www.hc-sc.gc.ca/fn-an/surveill/nutrition/commun/art-nutradol-eng.php (accessed June 2018).

38. Shamah-Levy T, Villalpando S, Jáuregui A et al. (2012) Overview of the nutritional status of selected micronutrients in Mexican children in 2006. Salud Publica Mex 54, 146-151.

39. Laillou A, Pham T, Tran N et al. (2012) Micronutrient deficits are still public health issues among women and young children in Vietnam. PLoS One 7, e34906.

40. D'Ambrosio A, Tiessen A \& Simpson J (2012) Development of a food frequency questionnaire for toddlers of lowGerman-speaking Mennonites from Mexico. Can J Diet Pract Res 73, 40-44.

41. Ward L, Gaboury I, Ladhani M et al. (2007) Vitamin D-deficiency rickets among children in Canada. CMAJ 177, 161-166.

42. Omand J, Darling P, Parkin P et al. (2013) Non-Western immigrant children have lower 25-hydroxyvitamin D than children from Western families. Public Health Nutr 17, 1547-1554

43. Bonjour JP \& Rizzoli R (2001) Bone acquisition in adolescence. In Osteoporosis, 2nd ed., pp. 621-638 [R Marcus, D Feldman and J Kelsey, editors]. San Diego, CA: Academic Press.

44. Sayers A, Fraser W, Lawlor D et al. (2012) 25Hydroxyvitamin- $\mathrm{D}_{3}$ levels are positively related to subsequent cortical bone development in childhood: findings from a large prospective cohort study. Osteoporos Int 23, $2117-2128$.

45. Institute of Medicine, Panel on Micronutrients (2001) Dietary Reference Intakes for Vitamin A, Vitamin K, Arsenic, Boron, Chromium, Copper, Iodine, Iron, Manganese, Molybdenum, Nickel, Silicon, Vanadium, and Zinc. Washington, DC: National Academies Press.

46. Walravens P, Krebs N \& Hambidge K (1983) Linear growth of low income preschool children receiving a zinc supplement. Am J Clin Nutr 38, 195-201.

47. Oberleas D, Muhrer M \& O'Dell B (1966) Dietary metalcomplexing agents and zinc availability in the rat. $J$ Nutr 90, 56-62.

48. King J \& Keen C (1999) Zinc. In Modern Nutrition in Health and Disease, 9th ed., pp. 223-239 [M Shils, J Olson, M Shike et al., editors]. Baltimore, MD: Lippincott, Williams and Wilkins.

49. Institute of Medicine (1998) Dietary Reference Intakes for Thiamin, Riboflavin, Niacin, Vitamin $\mathrm{B}_{6}$, Folate, Vitamin B12, Pantothenic Acid, Biotin, and Choline. https://www. ncbi.nlm.nih.gov/books/NBK114310/ (accessed June 2018).

50. Lozoff B (2007) Iron deficiency and child development. Food Nutr Bull 28, 4 Suppl., S560-S571.

51. Jáuregui-Lobera I (2014) Iron deficiency and cognitive functions. Neuropsychiatr Dis Treat 10, 2087-2095.

52. Cook J, Reddy M, Burri J et al. (1997) The influence of different cereal grains on iron absorption from infant cereal foods. Am J Clin Nutr 65, 964-969.

53. Hassan K, Sullivan K, Yip R et al. (1997). Factors associated with anemia in refugee children. J Nutr 127, 2194-2198. 